\title{
Atividade antifúngica de isolados clínicos de Candida não-albicans aos óleos essenciais de Syzygium aromaticum (cravo-da-índia) e Eucalyptus globulus (eucalipto-comum)
}

\author{
Antifungal activity of clinical isolates of Candida non-albicans to the essential \\ oils of Syzygium aromaticum (cloud) and Eucalyptus globulus (eucalyptus) \\ Claudio José dos Santos Júnior ${ }^{1}$ (D), Dálity Keffelen de Barros Rodrigues ${ }^{2}$ (D), Rita Dâmaris Soares Dantas ${ }^{3}$ (D), \\ Aryanna Kelly Pinheiro Souza ${ }^{4}$ (iD)
}

\begin{abstract}
RESUMO
Introdução: O gênero Candida possui alta taxa de incidência no ser humano, sendo a espécie Candida albicans a mais isolada em infecções invasivas e superficiais. Porém, tem sido relatado um aumento considerável de espécies de Candida não-albicans em infecções fúngicas. Os óleos essenciais, por serem voláteis, podem agir como sinais de comunicação química e arma de defesa. Objetivo: Avaliar a eficácia, in vitro, dos óleos essenciais de Syzygium aromaticum e Eucalyptus globulus na inibição do crescimento de espécies de Candida não-albicans. Métodos: Para avaliação da atividade antifúngica de $S$. aromaticum e de $E$. globulus e do efeito dos seus óleos essenciais sobre a micromorfologia das espécies Candida krusei, Candida parapsilosis e Candida glabrata, foram empregadas, nesta ordem, a técnica de difusão em ágar e de microcultivo para leveduras. Resultados: Na técnica de difusão, o óleo essencial de S. aromaticum apresentou formação de halo de inibição para Candida krusei, Candida parapsilosis e Candida glabrata. O óleo de E. globulus, por sua vez, não apresentou crescimento de halos de inibição em nenhuma das concentrações testadas frente às três espécies de Candida não-albicans. Todavia, com o microcultivo, ambos os óleos essenciais se provaram, in vitro, eficazes antimicrobianos tendo apresentado estruturas indicativas de atividade antifúngica na maior concentração dos óleos e diferentes graus de destruição celular nas demais concentrações. Conclusão: Nas condições deste estudo, concluiu-se que os produtos avaliados exerceram atividade antifúngica contra cepas de Candida não-albicans, destacando-se o óleo essencial de S. aromaticum que apresentou atividade antimicrobiana em ambas as metodologias.
\end{abstract}

Palavras-Chave: Candida glabrata; Candida parapsilosis; Candida tropicalis; Syzygium; Eucalyptus globulus.

\begin{abstract}
Introduction: The genus Candida possesses a high incidence of infection in humans, with the Candida albicans species being the most isolated in invasive and superficial infections. However, a considerable increase in non-albicans Candida species has been reported in fungal infections. Essential oils, for being volatile, can act as chemical communication signals and defense mechanisms. Objective: Evaluate the effectiveness, in vitro, of the essential oils of Syzygium aromaticum and Eucalyptus globulus in inhibiting the growth of non-albicans Candida species. Methods: To evaluate the antifungal activity of S. aromaticum and E. globulus and the effect of their essential oils on the micromorphology of the species Candida krusei, Candida parapsilosis and Candida glabrata, in this order, the agar diffusion technique and microculture for yeasts. Results: In the diffusion technique, the essential oil of S. aromaticum presented an inhibition halo for Candida krusei, Candida parapsilosis, and Candida glabrata. E. globulus oil, on the other hand, did not show inhibition halo growth in any of the concentrations tested against the three non-albicans Candida species. However, in the microculture, both essential oils have proven to be effective antimicrobials having shown structures indicative of antifungal activity in the highest concentration and different degrees of cell destruction in the other concentrations. Conclusion: In the conditions of this study, it was concluded that the products evaluated exerted antifungal activity against non-albicans Candida strains, highlighting the essential oil of $S$. aromaticum that showed antimicrobial activity in both methodologies.
\end{abstract}

Keywords: Candida glabrata; Candida parapsilosis; Candida tropicalis; Syzygium; Eucalyptus globulus.

Médico. Universidade Estadual de Ciências da Saúde de Alagoas (UNCISAL), Maceió (AL), Brasil.

Biomédica. Mestranda em Ciências na área de Vigilância em Saúde Pública, realizando a pesquisa no Instituto Adolfo Lutz, no núcleo de micologia com bolsa FAPESP. São Paulo (SP), Brasil.

3 Biomédica. Especialista em Microbiologia Laboratorial. Faculdade de Ciências Biológicas e da Saúde, Centro Universitário CESMAC, Maceió (AL), Brasil.

4 Mestre em Ciências da Saúde. Especialista em Micologia. Analista em Medicina Laboratorial e Microbiologia da Universidade Estadual de Ciências da Saúde de Alagoas (UNCISAL). Professora do Centro Universitário CESMAC, Maceió (AL), Brasil. 


\section{INTRODUÇÃO}

As leveduras do gênero Candida colonizam e infectam o ser humano com alta incidência, tornando-se de grande interesse na clínica médica ${ }^{1}$. A Candida albicans é a espécie mais comumente isolada em infecções invasivas e superficiais na rotina dos laboratórios de análises microbiológicas ${ }^{2}$. É relatada, ainda, como um agente com sensibilidade natural a uma grande variedade de drogas antifúngicas de uso sistêmico ${ }^{3-5}$. As espécies de Candida não-albicans, por sua vez, por apresentarem aderência e propriedades hidrofóbicas de maior patogenicidade e virulência, sendo descritas como grupos consideravelmente superiores a C. albicans ${ }^{6}$.

Em relação à terapêutica, as espécies de leveduras não-albicans caracterizam-se por apresentar particularidades quanto a sua sensibilidade aos diversos antifúngicos ${ }^{4,6}$. Isolados de Candida krusei são completamente resistentes ao fluconazol. Amostras de $C$. glabrata, com frequência, são resistentes ou necessitam da administração de doses maiores de azólicos ${ }^{7,8}$. Esses fenômenos decorrem, em parte, do uso indiscriminado de antifúngicos e podem resultar na seleção de cepas mais resistentes, que não são controladas e/ou eliminadas pelas terapêuticas usualmente empregadas. Tais problemas podem gerar consequências como aumento de custos, prolongamento da permanência em unidades hospitalares, aumento dos índices de mortalidade e insucesso terapêutico.

A preocupação com a resistência e, ao mesmo tempo, com a toxicidade dos antifúngicos fez surgir importantes trabalhos relacionados com a atividade antifúngica de produtos vegetais, destacando-se os estudos realizados por Lima et al. (2006) ${ }^{9}$, Oliveira et al. (2011) ${ }^{10}$, Santos et al. (2018) ${ }^{11}$, Serra et al. $(2018)^{12}$, Maciel et al. (2019) ${ }^{13}$, em que foram testados compostos derivados de produtos naturais contra várias espécies de fungos. Existe uma tendência de pesquisas desenvolvidas na atualidade com a obtenção de princípios ativos contidos nas espécies vegetais para tratamento de variadas infecções, incluindo as micoses ${ }^{14}$.

Dentre os compostos naturais em potencial, merecem destaque os óleos essenciais, produtos voláteis que, por possuírem tal característica, atuam como sinalizadores químicos, agentes de defesa, inibidores da germinação e na atração de polinizadores biológicos ${ }^{15}$. Alguns óleos vegetais têm sido utilizados em pesquisas na tentativa de buscar reconhecer sua atividade antifúngica e antibacteriana, como é o caso do Syzygium aromaticum - popularmente conhecido como cravo-da-índia e que apresenta como principal componente o eugenol, e do óleo de Eucalyptus globulus, espécie vegetal conhecida como eucalipto comum.

A atividade antimicrobiana dos óleos essenciais de $S$. aromaticum e E. globulus é evidenciada por alguns estudos ${ }^{16,17}$. Porém, existe uma escassez de informações referentes a sua atividade contra espécies de Candida não-albicans. Tendo em vista tal lacuna, além da crescente busca por alternativas de tratamento devido ao aumento da resistência das espécies não-albicans aos medicamentos convencionais e da carência de trabalhos que apontem a eficácia dos óleos essenciais sobre essas espécies, objetivou-se, neste estudo, avaliar a atividade antifúngica dos óleos essenciais de $S$. aromaticum e $E$. globulus frente a espécies de Candida não-albicans.

\section{MATERIAL E MÉTODOS}

\section{Amostragem}

Para o ensaio da atividade antifúngica dos óleos essenciais $S$. aromaticum e E. globulus utilizaram-se três espécies de Candida não-albicans que foram cedidas e estavam estocadas sob óleo mineral na Coleção de Culturas do Departamento de Micologia da Universidade Federal de Pernambuco (Candida parapsilosis; URM5583), (C. glabrata; URM5594) e (C. kruzei; URM1059). Os óleos de S. aromaticum (L.) e E. globulus (L) foram obtidos na Fórmula Ind. e Cosm. Ltda. ${ }^{\circledR}$ (Maceió-AL, Brasil).

\section{Reativação e purificação das espécies de Candida não-albicans}

Para reativação, as amostras de Candida não-albicans foram semeadas em caldo glicosado $20,0 \mathrm{~g} / \mathrm{mL}$ (CeQuímica, Brasil). Após o crescimento, foi efetuado repique para o meio de cultura ágar Sabouraud (Kasvi, Brasil) contido em tubo 
de ensaio. Transcorrido o período de crescimento, foram preparadas suspensões em água destilada esterilizada adicionada de antibiótico cloranfenicol 50 mg/L (Inlab, SP) e semeadas em ágar Sabouraud (Laborclin, Brasil) contido em placas de Petri através da técnica de esgotamento. As amostras foram mantidas à temperatura ambiente $\left( \pm 28^{\circ} \mathrm{C}\right)$ para confirmação da cultura pura e, posteriormente, foram semeadas.

\section{Preparo das amostras dos óleos essenciais}

Utilizou-se o método de diluição descrito por Aligiannis et al. ${ }^{27}$, no qual foram adicionados em tubos de vidro estéril: $1,6 \mathrm{~mL}$ do óleo essencial; 0,04 mL de Tween 80 (0,5\%; Fórmula Ind. e Cosm. Ltda. ${ }^{\circledR}$ Maceió-AL); e $5 \mathrm{~mL}$ de água destilada estéril. $O$ conjunto foi agitado durante 5 minutos em aparelho agitador de soluções tipo Vortex (Kasvi K4528-10, Brasil) e a concentração final obtida foi de $320 \mu \mathrm{L} / \mathrm{mL}$ (solução-padrão inicial). Para a avaliação da Concentração Inibitória Mínima (CIM) dos óleos essenciais, os produtos foram diluídos de forma seriada, de modo que foram preparadas mais seis soluções mediante emprego da técnica da microdiluição da solução-padrão, de modo que foram obtidas soluções ajustadas para os óleos essenciais nas concentrações finais de $320,160,80,40,20,10,5 \mu \mathrm{L} / \mathrm{mL}$. Essas concentrações foram padronizadas por Souza (2010) ${ }^{33}$ em trabalho cujo objetivo foi avaliar a atividade antifúngica dos óleos essenciais e fitoconstituintes obtidos de plantas medicinais referenciadas pela medicina popular.

\section{Avaliação da atividade antifúngica - Difusão em ágar}

Em placas esterilizadas, foi depositado $1 \mathrm{~mL}$ da suspensão padronizada do microrganismo e adicionados $21 \mathrm{~mL}$ do meio sólido fundido a $45-50{ }^{\circ} \mathrm{C}$. Após solidificação, foram feitas cavidades de $6 \times 8 \mathrm{~mm}$ de diâmetro, onde foram depositados $50 \mu \mathrm{L}$ de cada óleo essencial solubilizado em dimetilsulfóxido 10\% (DMSO; Vetec, Brasil) e que possuíam, no final, concentrações de
$320,160,80,40,20,10,5 \mu \mathrm{L} / \mathrm{mL}$. Cada amostra a ser testada foi preparada em tubos de ensaios ( $120 \times 12 \mathrm{~mm}$ de diâmetro) estéreis. Foram feitos controles para testes, sendo adotado controle negativo (DMSO na concentração de $100 \mu \mathrm{g} / \mathrm{mL}$ ) e positivo (cetoconazol $100 \mu \mathrm{g} / \mathrm{mL}$ e anfotericina B $128 \mu \mathrm{g} / \mathrm{mL}$; Cecon-Brasil). As placas foram incubadas a $37^{\circ} \mathrm{C}$ por 24 horas. Os testes foram realizados em triplicado para se obter no final, a média aritmética da CIM.

A determinação do efeito antifúngico dos óleos essenciais sobre as espécies de Candida foi determinada a partir da observação da presença ou ausência de crescimento e do tamanho do halo formado, medido com auxílio de halômetro. A metodologia utilizada foi normatizada pelo documento CLSI M31-A3 ${ }^{18}$. Os halos de inibição do crescimento microbiano foram medidos em milímetros $(\mathrm{mm})$ com auxílio de uma régua milimetrada. Foi considerada como CIM a menor concentração capaz de inibir o desenvolvimento dos microrganismos, com halos de $\geq 10 \mathrm{~mm}$ de diâmetro.

\section{Avaliação da morfologia - Microcultivo em lâmina}

O screening microbiológico da atividade antifúngica dos óleos essenciais sobre a micromorfologia das espécies não-albicans foi realizado baseado na técnica de microcultivo em lâmina para leveduras utilizando o meio ágar Fubá em câmara úmida conforme descrito por Koneman ${ }^{19}$.

Para a sua realização, foram adicionados nos meios $50 \mu \mathrm{g} / \mathrm{mL}$ das emulsões de cada óleo essencial ao meio de cultura ágar Fubá (Laborclin, Brasil) nas variadas concentrações dos produtos. Foram depositados $3 \mathrm{~mL}$ de ágar Fubá associados aos produtos teste e fundidos sobre uma lâmina estéril, contido sobre um suporte (outra lâmina) dentro de uma placa de Petri. Após solidificação do meio foi semeada a levedura com auxílio de uma agulha em $L$, fazendo duas estrias paralelas. As estrias foram cobertas com lamínulas esterilizadas. Para evitar ressecamento do meio foi preparado uma câmara úmida acrescentando $2 \mathrm{~mL}$ de água destilada sobre um pedaço de papel de filtro $(3 \times 3 \mathrm{~cm})$ estéril na placa durante o período de incubação. 
Em cada placa do teste foram incluídos controles positivos (cetoconazol $50 \mathrm{mg}$; anfotericina B $100 \mathrm{mg}$; Cecon-Brasil) e controle negativo representado pela ausência de óleos essenciais e de fungo. A placa foi fechada e, após $24 \mathrm{~h}$, a preparação foi examinada em microscópio óptico.

A determinação do efeito antifúngico dos óleos essenciais sobre a morfologia das espécies de Candida foi realizada através da observação em microscópio em aumento de 400x. Todos os experimentos foram realizados em triplicado.

\section{Análise dos dados}

Fora empregada estatística de frequência absoluta e relativa para análise dos resultados obtidos nos testes, utilizando o software BioEstat (Instituto Mamirauá, v. 5.0). Os resultados foram agrupados em tabelas e a discussão dos achados foi realizada à luz da literatura especializada.

\section{RESULTADOS}

Nos ensaios de determinação da CIM do óleo essencial de $S$. aromaticum através da técnica de difusão em meio sólido com discos de papel de filtro, os diâmetros dos halos de inibição variaram de 9 a $20 \mathrm{~mm}$.

Na Tabela 1 são apresentadas as médias dos halos de inibição do óleo essencial de $S$. aromaticum e do controle positivo (anfotericina B) sobre as espécies de Candida não-albicans.

Na técnica de difusão em ágar, o óleo de E. globulus não apresentou crescimento de halos de inibição em nenhuma das concentrações testadas.

Nas Tabelas 2 e 3 são apresentados os resultados obtidos através da técnica de microcultivo, nas diferentes diluições do óleo de $E$. globulus e do óleo de $S$. aromaticum, respectivamente.

Na Figura 1 apresentamos os resultados da observação em microscópio da espécie Candida parapsilosis frente ao microcultivo do óleo de Eucalyptus globulus.

Tabela 1

Média dos halos de inibição do óleo essencial de Syzygium aromaticum sobre Candida não-albicans.

\begin{tabular}{lcccccc}
\hline \multirow{2}{*}{ Espécies de Candida } & \multicolumn{3}{c}{ Controles } & \multicolumn{3}{c}{ Concentração do óleo essencial } \\
\cline { 2 - 7 } & N & CP* & CP** & $\mathbf{3 2 0} \boldsymbol{\mu L / m L}$ & $\mathbf{1 6 0} \boldsymbol{\mu L / m L}$ & $\mathbf{8 0} \boldsymbol{\mu L / m L}$ \\
\hline C. krusei & AF & 5 & 26 & $20 \mathrm{~mm}$ & $12 \mathrm{~mm}$ & $\mathrm{AF}$ \\
C. parapsilosis & AF & AF & 23 & AF & AF & AF \\
C. glabrata & AF & AF & 20 & $18 \mathrm{~mm}$ & $15,5 \mathrm{~mm}$ & $9 \mathrm{~mm}$ \\
\hline
\end{tabular}

Legenda: *Controle Positivo (cetoconazol $100 \mu \mathrm{g} / \mathrm{mL}$ ); ${ }^{* \star}$ Controle Positivo (anfotericina B $128 \mu \mathrm{g} / \mathrm{mL}$ ); N: Controle negativo; AF: ausência de formação de halo de inibição.

\section{Tabela 2}

Microcultivo nas diluições do óleo de Eucalyptus globulus.

\begin{tabular}{|c|c|c|c|}
\hline $\begin{array}{c}\text { Solução } \\
\text { (Concentração) }\end{array}$ & C. krusei & C. glabrata & C. parapsilosis \\
\hline $320 \mu \mathrm{L} / \mathrm{mL}$ & Raras leveduras c/blastoconídios & Raras leveduras c/blastoconídios & Morte celular \\
\hline $160 \mu \mathrm{L} / \mathrm{mL}$ & Poucas leveduras c/blastoconídios & Poucas leveduras c/blastoconídios & Raras leveduras \\
\hline $80 \mu L / m L$ & Leveduras c/ blastoconídios ${ }^{1}$ & Estrutura normal & Poucas leveduras c/ blastoconídios \\
\hline $40 \mu L / m L$ & Leveduras c/blastoconídios & Estrutura normal2 & Leveduras c/blastoconídios \\
\hline $20 \mu L / m L$ & Estrutura normal ${ }^{1}$ & Estrutura normal ${ }^{2}$ & Leveduras c/blastoconídios \\
\hline $10 \mu \mathrm{L} / \mathrm{mL}$ & Estrutura normal ${ }^{1}$ & Estrutura normal2 & Leveduras c/blastoconídios \\
\hline $5 \mu L / m L$ & Estrutura normal ${ }^{1}$ & Estrutura normal ${ }^{2}$ & Leveduras c/blastoconídios \\
\hline
\end{tabular}

Legenda: 1: Leveduras com blastoconídios, pseudo-hifas e hifas verdadeiras; 2: Leveduras com blastoconídios. 

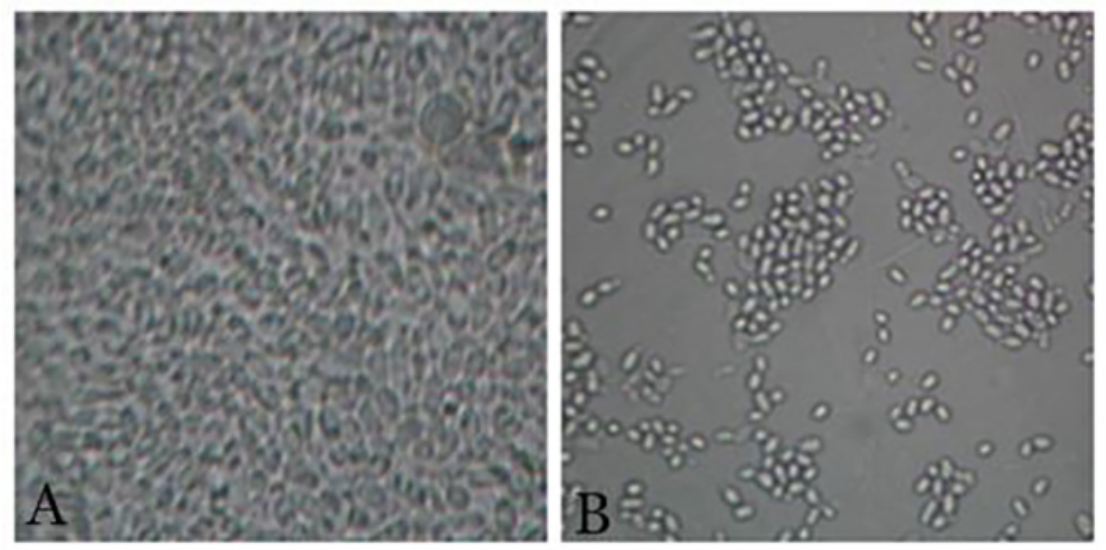

Legenda: A: Diluição $320 \mu \mathrm{L} / \mathrm{mL}$ evidenciando morte celular total; B: Diluição $5 \mu \mathrm{L} / \mathrm{mL}$ evidenciando leveduras com blastoconídios.

Figura 1: Morfologia da Candida parapsilosis frente ao microcultivo do óleo de Eucalyptus globulus.

\section{Tabela 3}

Microcultivo nas diluições do óleo de Syzygium aromaticum

\begin{tabular}{|c|c|c|c|}
\hline $\begin{array}{c}\text { Solução } \\
\text { (Concentração) }\end{array}$ & C. krusei & C. glabrata & C. parapsilosis \\
\hline $320 \mu \mathrm{L} / \mathrm{mL}$ & $\begin{array}{c}\text { Raras leveduras c/ blastoconídios, } \\
\text { raras pseudo-hifas }\end{array}$ & $\begin{array}{l}\text { Raras leveduras c/ } \\
\text { blastoconídios }\end{array}$ & $\begin{array}{l}\text { Raras leveduras c/ } \\
\text { blastoconídios }\end{array}$ \\
\hline $160 \mu \mathrm{L} / \mathrm{mL}$ & $\begin{array}{c}\text { Raras leveduras c/ blastoconídios, } \\
\text { poucas hifas }\end{array}$ & $\begin{array}{l}\text { Raras leveduras c/ } \\
\text { blastoconídios }\end{array}$ & $\begin{array}{l}\text { Poucas leveduras c/ } \\
\text { blastoconídios }\end{array}$ \\
\hline $80 \mu L / m L$ & $\begin{array}{l}\text { Raras leveduras c/ blastoconídios, } \\
\text { poucas hifas }\end{array}$ & $\begin{array}{l}\text { Poucas leveduras c/ } \\
\text { blastoconídios }\end{array}$ & $\begin{array}{c}\text { Poucas leveduras c/ } \\
\text { blastoconídios e poucas hifas }\end{array}$ \\
\hline $40 \mu \mathrm{L} / \mathrm{mL}$ & $\begin{array}{l}\text { Raras leveduras c/ blastoconídios, } \\
\text { poucas hifas }\end{array}$ & $\begin{array}{l}\text { Poucas leveduras c/ } \\
\text { blastoconídios }\end{array}$ & $\begin{array}{c}\text { Poucas leveduras c/ } \\
\text { blastoconídios e poucas hifas }\end{array}$ \\
\hline $20 \mu \mathrm{L} / \mathrm{mL}$ & $\begin{array}{l}\text { Poucas leveduras c/ blastoconídios, } \\
\text { poucas hifas }\end{array}$ & Estrutura normal ${ }^{1}$ & $\begin{array}{c}\text { Algumas leveduras c/ } \\
\text { blastoconídios e algumas hifas }\end{array}$ \\
\hline $10 \mu \mathrm{L} / \mathrm{mL}$ & $\begin{array}{c}\text { Poucas leveduras c/ blastoconídios, } \\
\text { poucas hifas }\end{array}$ & Estrutura normal ${ }^{1}$ & $\begin{array}{l}\text { Algumas leveduras c/ } \\
\text { blastoconídios e algumas hifas }\end{array}$ \\
\hline $5 \mu \mathrm{L} / \mathrm{mL}$ & $\begin{array}{c}\text { Poucas leveduras c/ blastoconídios, } \\
\text { poucas hifas }\end{array}$ & Estrutura normal ${ }^{1}$ & $\begin{array}{l}\text { Algumas leveduras c/ } \\
\text { blastoconídios e algumas hifas }\end{array}$ \\
\hline
\end{tabular}

Legenda: 1: Leveduras com blastoconídios.

\section{DISCUSSÃO}

A atividade antifúngica dos óleos essenciais é considerada positiva quando a média aritmética dos halos de inibição alcançar valores superiores ou iguais a $10 \mathrm{~mm}$ de diâmetro ${ }^{6}$.

A C. krusei apresentou o maior halo (20 mm) na concentração de $320 \mu \mathrm{L} / \mathrm{mL}$, seguida da C. glabrata com halo de $18 \mathrm{~mm}$. As duas espécies mostraram um CIM de $160 \mu \mathrm{L} / \mathrm{mL}$, com halos de 12 e 15,5 mm, respectivamente. Nesta última espécie foi visualizada um halo de resistência $(9 \mathrm{~mm})$ na diluição de $80 \mu \mathrm{L} / \mathrm{mL}$.
A espécie $C$. parapsilosis foi a única que não apresentou sensibilidade.

Verificou-se, portanto, que o óleo essencial de Syzygium aromaticum apresentou resultados satisfatórios frente às espécies $C$. krusei e a $C$. glabrata, dados que corroboram com estudo que relatou atividade antifúngica do princípio ativo do cravo-da-índia ${ }^{20}$.

Diante desta mesma técnica, difusão de meio, o óleo de E. globulus não apresentou resultados satisfatórios, apresentando baixa efetividade antifúngica, expressa pelo não crescimento de halos de inibição em nenhuma das concentrações testadas. Tal achado já havia sido citado em trabalho 
cujo objetivo foi determinar a atividade antifúngica de um conjunto de óleos essenciais, entre os quais estava o óleo de Eucalyptus globulus, sobre espécies de Candida ${ }^{21}$. Importante enfatizar a possibilidade de esse resultado ter sido influenciado por características intrínsecas desse grupo de óleos vegetais, tais como volatilidade, insolubilidade e complexidade química e/ou por interferências exteriores ${ }^{22}$.

No controle positivo (anfotericina B), as três espécies de Candida testadas apresentaram sensibilidade. No controle positivo (cetoconazol), todas as espécies de Candida apresentaram resistência. Isso reforça a pesquisa de Castro et al. ${ }^{23}$ que relata a resistência das cepas de $C$. kruzei e $C$. glabrata frente a antifúngicos do grupo dos azóis, como o cetoconazol, uma das drogas utilizadas nesta pesquisa como controle positivo.

Os resultados aqui encontrados para a resistência do cetoconazol foram distintos dos relatados por Menezes et $a^{24}$. sobre cepas de $C$. parapsilosis em que fora verificada sensibilidade ao antifúngico cetoconazol. Esse fenômeno vem sendo atribuído ao uso abusivo de tais drogas que tornam estas espécies mais resistentes por meio de seleção natural e adaptações. A sensibilidade das cepas de Candida examinadas ao poliênico à anfotericina B também foi constada em trabalho anterior desenvolvido por Furtado et al. (1997) ${ }^{25}$.

$\mathrm{Na}$ avaliação do efeito do óleo essencial de $E$. globulus sobre a morfologia das espécies de Candida utilizando microcultivo em lâmina foram obtidos resultados satisfatórios para todas as espécies testadas. A espécie que apresentou melhor resultado foi a C. parapsilosis, tendo sido observada morte celular total na maior concentração do óleo de E. globulus e diferentes graus de destruição celular nas demais concentrações. C. krusei e C. glabrata também apresentaram resultados satisfatórios, especialmente nos testes em que foram empregadas concentrações mais elevadas do óleo de $E$. globulus em que fora possível a visualização de raras leveduras com blastoconídios estruturas que são indicativos de atividade antifúngica de alta capacidade e de maioria das estruturas morfológicas do microrganismo ${ }^{26}$. Nas menores concentrações $(5,10$ e $20 \mu \mathrm{L} / \mathrm{mL})$ não foi visualizada interferência do óleo na morfologia das espécies de Candida não-albicans. Tais achados evidenciam a capacidade antifúngica desse derivado vegetal, que não havia sido confirmada pela técnica anterior, provavelmente pelo método de difusão em ágar estar exposto a uma maior influência de interferências exteriores.
Na técnica de microcultivo, nas diferentes diluições do óleo de S. aromaticum, foram visualizadas de poucas a raras leveduras com blastoconídios com hifas. Todas as três espécies de Candida na concentração de $320 \mu \mathrm{L} / \mathrm{mL}$ apresentaram raras estruturas. Novamente, nesta metodologia, a C. parapsilosis mostrou-se mais sensível em relação às demais cepas, havendo perda de estruturas celular em todas as concentrações do óleo de S. aromaticum. A C. Krusei também exibiu destruição celular, no entanto, em menor proporção em relação à $C$. parapsilosis. A C. glabrata nas diluições de $5 \mu \mathrm{L} / \mathrm{mL}$ a $20 \mu \mathrm{L} / \mathrm{mL}$ apresentou estrutura celular normal. Assim como no óleo de E. globulus, a C. glabrata se mostrou resistente nas menores concentrações $(5,10$ e $20 \mu \mathrm{L} / \mathrm{mL})$.

Em trabalho anterior cujo objetivo foi avaliar a atividade antifúngica do óleo essencial de folhas de Ocimum gratissimum sobre espécies de Candida spp. também foram constatadas alterações na micromorfologia das células fúngicas, com ênfase para redução no número de células e crescimento microbiano, sugerindo que seu alvo de ação, assim como nos óleos de E. globulus e $S$. aromaticum, seja o envoltório celular ${ }^{28}$. Acerca desse tema, Vieira et al. ${ }^{29}$ afirmam que essa ação antimicrobiana dos óleos essenciais tem relação direta com a caracterização química de seus componentes e citam o caráter lipofílico da cadeia de hidrocarbonetos e hidrófilo dos grupos funcionais como fatores de grande importância na composição desses produtos. Burt ${ }^{30}$ traz que compostos fenólicos como timol, carvacrol, cineol e o eugenol são consideradas substâncias com elevados potenciais antimicrobianos, fenômeno que pode ser explicado pela natureza ácida do grupo hidroxila dessas substâncias; essa estrutura forma uma ligação de hidrogênio com o centro ativo das enzimas dos micro-organismos, impedindo sua ação.

Nesse contexto, podemos inferir, que a ação antimicrobiana constatada dos óleos de $S$. aromaticum e E. globulus frente às cepas de Candida não-albicans seja atribuída, em grande parte, ao eugenol e ao cineol, respectivamente, componentes majoritários na constituição dos óleos essenciais em estudo ${ }^{31,32}$.

\section{CONCLUSÃO}

Na técnica de difusão, o óleo essencial de S. aromaticum apresentou halo de inibição para 
Candida krusei, Candida parapsilosis e Candida glabrata. O óleo de E. globulus, por sua vez, não apresentou crescimento de halos de inibição em nenhuma das concentrações testadas frente às três espécies de Candida não-albicans.

Todavia, com o microcultivo, ambos os óleos essenciais se provaram eficazes antimicrobianos tendo resultado em estruturas indicativas de alta atividade antifúngica na maior concentração dos produtos e diferentes graus de destruição celular nas demais concentrações.

A C. parapsilosis, dentre as cepas de Candida não-albicans testadas, apresentou a maior sensibilidade aos dois óleos, sendo a única espécie a ter morte celular total com o óleo de Eucalipto. Ao compararmos o microcultivo dos dois óleos essenciais, o óleo de $S$. aromaticum teve maior desempenho geral comparado ao óleo de E. globulus, com a exceção na C. parapsilosis.

Nas condições deste estudo, concluiu-se que os produtos avaliados exerceram atividade antifúngica, in vitro, contra cepas de Candida não-albicans, destacando-se o óleo essencial de $S$. aromaticum que apresentou atividade antimicrobiana em ambas as metodologias. Estudos adicionais são necessários para comparar os efeitos in vitro e in vivo de formulações que contenham E. globulus e S. aromaticum com vistas a um potencial desenvolvimento de formulações para o tratamento de doenças fúngicas que tenham como base tais compostos.

\section{REFERÊNCIAS}

1. Deorukhkar SC, Saini S. Non albicans Candida species: A review of epidemiology, pathogenicity and antifungal resistance. Pravara Med Rev. 2015;7:7-15.

2. Sharma P, Kaur J, Sharma S. Prevalence of non-albicans Candida species versus Candida albicans in critical care patients of a tertiary care hospital. Trop J Path Micro $2016 ; 2(3): 89-93$

3. Gonçalves SS, Souza AC, Chowdhary A, Meis JF, Colombo AL. Epidemiology and molecular mechanisms of antifungal resistance in Candida and Aspergillus. Mycoses. 2016;59:198-219.

4. Vieira F, Nascimento T. Candida Antifungal Resistance and Therapeutic Approach. Rev Port Farmacoter 2017;9(3):161168.DOI: https://doi.org/10.25756/rpf.v9i3.158.

5. Sanguinetti M, Posteraro B. Susceptibility Testing of Fungi to Antifungal Drugs. J. Fungi $2018 ; 4(3): 110$. https://doi.org/10.3390/jof4030110.

6. Deorukhkar SC, Saini S. Virulence factors attributed to pathogenicity of non albicans Candida species isolated from Human Immunodeficiency virus infected patients with oropharyngeal candidiasis. Ann Pathol Lab Med.2015;2(2):62-66.

7. National Committee for Clinical Laboratory Standards (CLSI). Document M27-S4. Método de referência para testes de susceptibilidade antifúngica à diluição em caldo de leveduras; quarto suplemento informativo. Wayne: Clinical and Laboratory Standards Institute, 2012.

8. Silva MGC, Rodrigues GS, Gonçalves IL, Grazziotin NA. Candida species distribution and fluconazole susceptibility of blood isolates at a regional hospital in Passo Fundo, RS, Brazil. J. Bras. Patol. Med. Lab. 2015; 51(3):158-161. https://dx.doi. org/10.5935/1676-2444.20150027.

9. Lima IO, Oliveira RAG, Lima EO, Farias NMP, Souza EL. Atividade antifúngica de óleos essenciais sobre espécies de Candida. Rev Bras Farmacogn. 2006;16:197-201.

10. Oliveira WA, Pereira FO, Luna GCDG, Lima IO, Wanderley PA, Rita B et al. Atividade antifúngica de Cymbopogon winterianus jowitt ex bor contra Candida albicans. Braz. J. Microbiol. 2011;42(2): 433-441. ttp://dx.doi. org/10.1590/S1517-83822011000200004.

11. Santos JFSD, Rocha JE, Bezerra CF, Matos Y, Freitas TSD, Santos ATLD. Chemical composition, antifungal activity and potential anti-virulence evaluation of the Eugenia uniflora, essential oil against Candida, spp. Food Chemistry 2018. 261;233-239. https://doi. org/10.1016/j.indcrop.2014.05.052

12. Serra E, Hidalgo-Bastida EA, Verran J, Williams D, Malic. Activity of Commercial Essential Oils and Biocides against Candida Albicans. Pathogens 2018; 7(1):15. https://doi.org/10.3390/pathogens7010015

13. Maciel AJ, Lacerda CP, Danielli LJ, Bordignon SAL, Fuentefria AM, Apel MA. Antichemotactic and Antifungal Action of the Essential Oils from Cryptocarya aschersoniana, Schinus terebinthifolia, and Cinnamomum amoenum. Chem Biodivers. 2019;16(8):e1900204. https://dx.doi.org/10.1002/cbdv.201900204.

14. Lopes G, Pinto E, Salgueiro L. Natural Products: An Alternative to Conventional Therapy for Dermatophytosis? Mycopathologia. 2017;182(2):143167. https://doi.org/10.1007/s11046-016-0081-9.

15. Nazzaro F, Fratianni F, Coppola R, Feo V. Essential Oils and Antifungal Activity. Pharmaceuticals. 2017;10(4)86. https://doi.org/10.3390/ph10040086.

16. Marchese A, Barbieri R, Coppo E, Orhan IE, Daglia M, Nabavi SF et al. Antimicrobial activity of eugenol and essential oils containing eugenol: A mechanistic viewpoint. Crit. Rev. Microbiol. 2017;43;668-689.

17. Dhakad AK, Pandey VV, Beg S, Rawat JM, Singh A. Biological, medicinal and toxicological significance of Eucalyptus leaf essential oil: a review. J Sci Food Agric. 2018;98(3):833848. https://doi.org/10.1002/jsfa.8600.

18. CLSI. Clinical and Laboratory Standards Institute. Antimicrobial disk and dilution susceptibility tests for bacteria isolated from animals. $3^{a}$ ed. Wayne, PA, CLSI document M31-A3, 2008.

19. Koneman EW. Diagnóstico Microbiológico-Texto e Atlas Colorido. 5. ed. Rio de Janeiro: Editora Médica e Científica, 2001.

20. Souza NAB. Possíveis mecanismos de atividade antifúngica de óleos essenciais contra fungos patogênicos. Tese (Doutorado em Produtos Naturais e Sintéticos Bioativos), UFPB, João Pessoa/PB, 2010. 150 p. 
21. Oliveira Lima I, Oliveira RDAG, Oliveira Lima E, Farias NMP, Souza EL. Atividade antifúngica de óleos essenciais sobre espécies de Candida. Brazilian Journal of Pharmacognosy, 2006;16(2):197-201.

22. Castro RD, Oliveira Lima E. Atividade antifúngica in vitro do óleo essencial de Eucalyptus globulus L. sobre Candida spp. Rev Odontol UNESP, 2010;39(3):179-184.

23. Castro TL, Coutinho HDM, Gedeon CC, Santos JD, Santana WJ, Souza LD. Mecanismos de resistência da Candida Sp. Wwa antifúngicos. Infarma 2006;18(9)10.

24. Menezes EA, Júnior AADV, Cunha FA, Cunha MCDSO, Braz BHL, CapelLG,Silva CLF. Identificação molecular e suscetibilidade antifúngica de Candida parapsilosis isoladas no Ceará, Brasil. J. Bras. Patol. Med. Lab. 2012; 48(6):415-420.

25. Furtado MSS, Pimenta DR, Ferreira JA, CORTEZ, AC. Comportamento de leveduras do gênero candida "in vitro" a antifúngicos. Acta Amaz. 1997; 27(3):169-174.

26. Brooks G, Carroll,K, Butel J, Morse S, Mietzner TJ. Microbiologia médica. $8^{a}$ ed. Rio de Janeiro: Editora McGraw-Hill; 2017.

27. Aligiannis N, Kalpoutzakis E, Mitaku S, Chinou JB. Composition and Antimicrobial Activity of the Essential Oils of Two Origanum Species. J Agric Food Chem. 2001;49(9):4168-70.

Reativação, isolamento e purificação

Ágar-Sabouraud $+50 \mathrm{mg} / \mathrm{L}$ de cloranfenicol

Dextrose $40,0 \mathrm{~g}$

Peptona $10,0 \mathrm{~g}$

Ágar $15,0 \mathrm{~g}$

Água destilada $1000 \mathrm{~mL}$

Cloranfenicol 50mg

Conflito de Interesses

Não há.

Fonte de fomento

Não se aplica.
28. Oliveira LBS, Batista AHM; Fernandes FC; Sales GWP; Nogueira NAP. Atividade antifúngica e possível mecanismo de ação do óleo essencial de folhas de Ocimum gratissimum (Linn.) sobre espécies de Candida. Rev. Bras. PI. Med., 2016;18(2)511-523.

29. Vieira PRN, Morais SM, Bezerra FHQ, Ferreira PAT, Oliveira OI, Silva MGV. Chemical composition and antifungal activity of essential oils from Ocimum species. Industrial Crops and Products. 2014;55(1):267-271.

30. Burt SA. Essential oils: their antibacterial properties and potential applications in foods - a review. International Journal of Food Microbiology. 2004;94(1)223-253.

31. Rabêlo, WF. Chemical, and toxicity antibacterial activity of essential oil of cloves (Syzygium aromaticum). Dissertação (Mestrado em Química), Universidade Federal do Maranhão, São Luis, 2010, 79 p.

32. Vilela GR. Efeito do óleo essencial de Eucalyptus globulus sobre espécies produtoras de aflatoxinas. Dissertação (Mestrado em Ciências), Universidade de São Paulo, Piracicaba, 2007, 65 p.

33. Souza, NAB. Possíveis mecanismos de atividade antifúngica de óleos essenciais contra fungos patogênicos. Dissertação (Mestrado em Produtos Naturais, Sintéticos e Bioativos), Universidade Federal da Paraíba, Piracicaba, 2010, $150 \mathrm{p}$

\section{Caldo glicosado}

Dextrose 20,0g

Peptona de carne $10,0 \mathrm{~g}$

Extrato de carne $15,0 \mathrm{~g}$

Água destilada $1000 \mathrm{~mL}$

$* \mathrm{pH}=6,8-7,0$
Aprovação do comitê de ética em pesquisa Não se aplica.

\section{Registro dos ensaios clínicos em base de acesso público}

Não se aplica.

Autor correspondente:

Aryanna Kelly Pinheiro Souza

aryannakelly@gmail.com

Editor:

Prof. Dr Felipe Villela Gomes

Recebido em: 11/04//2020

Aprovado em: 08/07/2020 